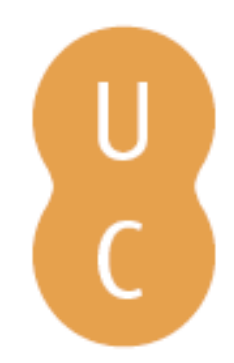

\title{
nommalina
}

\section{"Un certo giorno di un certo anno in Aulide" de Vico Faggi: el mito de Ifigenia como símbolo de resistencia al mal}

\author{
Autor(es): $\quad$ Cerrato, Daniele \\ Publicado por: Imprensa da Universidade de Coimbra; Annablume \\ URL \\ persistente: URI:http://hdl.handle.net/10316.2/40930 \\ DOI: $\quad$ DOI:https://doi.org/10.14195/978-989-26-1298-0_24 \\ Accessed : $\quad$ 26-Apr-2023 05:08:33
}

A navegação consulta e descarregamento dos títulos inseridos nas Bibliotecas Digitais UC Digitalis, UC Pombalina e UC Impactum, pressupõem a aceitação plena e sem reservas dos Termos e Condições de Uso destas Bibliotecas Digitais, disponíveis em https://digitalis.uc.pt/pt-pt/termos.

Conforme exposto nos referidos Termos e Condições de Uso, o descarregamento de títulos de acesso restrito requer uma licença válida de autorização devendo o utilizador aceder ao(s) documento(s) a partir de um endereço de IP da instituição detentora da supramencionada licença.

Ao utilizador é apenas permitido o descarregamento para uso pessoal, pelo que o emprego do(s) título(s) descarregado(s) para outro fim, designadamente comercial, carece de autorização do respetivo autor ou editor da obra.

Na medida em que todas as obras da UC Digitalis se encontram protegidas pelo Código do Direito de Autor e Direitos Conexos e demais legislação aplicável, toda a cópia, parcial ou total, deste documento, nos casos em que é legalmente admitida, deverá conter ou fazer-se acompanhar por este aviso.

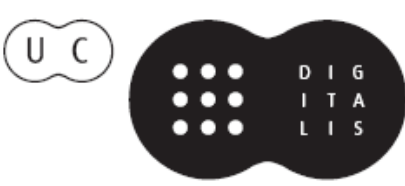




\section{O Livro do Tempo: \\ Escritas e reescritas}

\section{Teatro Greco-Latino e sua recepção II}

Maria de Fátima Silva, Maria do Céu

Fialho \& José Luís Brandão (coords.)

IMPRENSA DA UNIVERSIDADE DE COIMBRA 


\title{
“Un certo giorno di un certo anno in Aulide” de Vico Faggi. EL MITO DE IFIGENIA COMO SÍMBOLO DE RESISTENCIA AL MAL ("Un certo giorno di un certo anno in Aulide" of Vico Faggi. The myth of Iphigenia as a symbol of resistance to evil)
}

\author{
Daniele Cerrato (dcerrato@us.es) \\ Universidad de Sevilla, Facultad de Filología
}

\begin{abstract}
Resumen -Un certo giorno di un certo anno in Aulide es una obra de Vico Faggi publicada en 1965. Se trata de una obra en tres actos que ya se había representado en 1963 con el titulo de Ifigenia non deve morire. Vico Faggi revisita la historia narrada por Eurípides y a través del mito de Ifigenia se enfrenta con problemáticas como la responsabilidad civil, el concepto de patria, la religión y la superstición. Un certo giorno di un certo anno in Aulide se trasforma también en una reflexión sobre las diferentes maneras de contar y representar la historia y las posibilidades de resistir y luchar frente a la barbarie del mundo.
\end{abstract}

Palabras clave - Vico Faggi, Ifigenia, Eurípides, sacrificio, resistencia.

Abstract - Un certo giorno di un certo anno in Aulide is a play by Vico Faggi, published in 1965. It's a three-act play that was represented in 1963 with the title Ifigenia non deve morire. Vico Faggi revisits the story told by Euripides and through the myth of Iphigenia approaches to problems as civil responsibility, the concept of homeland, religion and superstition. Un certo giorno di un certo anno in Aulide turns into a reflection on different ways to tell and represent the history and the possibilities to resist and fight against the barbarity of the world.

KEywords - Vico Faggi, Iphigenia, Euripides, sacrifice, resistance.

El personaje de Ifigenia, durante todos estos siglos, no ha tenido tantas relecturas y no ha sido llevado a la escena con la misma frecuencia que otras heroínas clásicas como Medea, Fedra o Antígona.

La historia de Ifigenia, presente en el Agamenón de Esquilo y en la Ifigenia en Áulide de Eurípides, detrás del sacrificio de la protagonista, esconde un fuerte significado político. Hay que tener en cuenta que cuando Esquilo presenta su Orestíada, en el 458 a.C, Atenas está empeñada en las Guerras Delo-Áticas y es el centro de importantes decisiones políticas. También es significativo que Eurípides escriba su Ifigenia en Aulide en el 409 a.C, durante la última fase de la guerra del Peloponeso cuando ya tiene 80 años y se encuentra en la corte de Arquelao en Macedonia. Quizás tampoco es una casualidad que la obra de Eurípides se representará solo póstumamente, en el 406 a.C.

Ifigenia es un personaje con una fuerte connotación política porque entre los varios personajes femeninos de la antigüedad es ciertamente la figura que 
mejor representa el gran vínculo que existe entre la violencia del sacrificio y el sistema patriarcal. En su mito se concentran y se unen violencia verbal, violencia física y violencia psicológica. Ya en la etimología de su nombre se encuentran dos valores fundamentales del mundo griego ( $\gamma \varepsilon ́ v o \zeta$, 'estirpe', e $\tilde{i} \varphi \imath$ 'fuerza'). En el caso de Ifigenia, sobre todo en la versión de Eurípides, la protagonista abrazará estos valores, transformándose en el instrumento para defender y salvaguardar toda Grecia.

La búsqueda del consenso es un tema que ya caracteriza el Agamenón de Esquilo, donde el protagonista intenta consolidar su poder, apropiándose del sacrificio de la hija, de su dolor y su desgracia para transformarla en propaganda política y reforzar su posición. Agamenón juega con el doble papel de padre y jefe de los guerreros y se coloca la máscara que mejor se adapte a las diferentes circunstancias: es prisionero de su status de líder, de la sociedad de la honra y su papel de padre resulta una prolongación de este sistema.

En la Ifigenia en Aulide de Eurípides la cuestión del sacrificio se trasforma aún más en el símbolo del poder político masculino, y el ámbito de los afectos familiares viene tratado solo en parte. La acusación más grave que Menelao formula a su hermano Agamenón es no ser capaz de interpretar adecuadamente su papel de líder y no tener un carácter fuerte para ejercer su cargo. Agamenón, por lo tanto, queda aprisionado en la virilidad de un guerrero que tiene que mostrarse siempre fuerte e imperturbable y no puede dejar espacio a su intimidad. E1 sacrificio es sobre todo una cuestión ética y el jefe griego trasforma su imposición en algo natural y cultural.

Con respecto al texto de Esquilo, donde la protagonista se quedaba callada sin poder gritar su dolor, en la tragedia de Eurípides, Ifigenia tiene la posibilidad de hablar, pero su discurso se trasforma en un discurso declinado en masculino. De repente parece perder su visión libre y espontánea de juzgar el mundo, autocensurándose y siendo englobada por la sociedad patriarcal.

Entre otras, Anna Beltrametti (2008) destaca el significado político de la obra y sostiene que existen afinidades entre el personaje de Ifigenia y el de Antígona de Sófocles. Como Antígona se opone a Creonte y a sus leyes, Ifigenia, interpretando el papel de salvadora, intentaría compensar las carencias de su padre. Es necesario señalar que los valores y principios de los personajes son completamente diferentes. Si Antígona se pone en abierto conflicto con el poder político y elige una propia ley, Ifigenia, en cambio, se hace portavoz del mismo sistema que la rechaza. A pesar que el aspecto político presente en la obra no se puede obviar, las relecturas más importantes que se han realizado a lo largo de los siglos parecen infravalorar este aspecto y prefieren seguir otras líneas narrativas.

Algunos de los dramaturgos más importantes que se han acercado a esta figura han querido alejarse del sentido político de la versión de Esquilo y de 
Eurípides ${ }^{1}$. Racine, por ejemplo, en su versión de Ifigenia de 1642 reanuda una tercera versión del mito, donde aparece un doble de Ifigenia, Irifile, hija de Teseo y Elena. El autor francés insiste en el lado pasional de Ifigenia y cuando Agamenón, para salvarla, quiere obligarla a separarse de Aquiles, Ifigenia se dice dispuesta a morir. En el final de la tragedia será Irifile la que morirá en su lugar.

Johann Wolfang Goethe en su Ifigenia en Tauride, del 1787, representa una Ifigenia sacerdotisa que es una mujer más madura y sabia que, en su situación de exiliada, extraña a su patria y su familia. Será este sentimiento y destino común y la empatía que se crea con Orestes y Pílades lo que le permitirá salvarlos de una muerte cierta.

Por último, en El regreso de Ifigenia de Ghiannis Ritsos, el poeta griego representa la última fase de la vida de Ifigenia, que ha vuelto a Argo con Orestes y Pílades, pero entre los tres ya no existe la complicidad de un tiempo. Pílades se marchará y dejará solos a los dos hermanos incapaces de comunicar entre ellos.

En cambio, la obra de Vico Faggi (verdadero nombre Alessandro Orengo) Un certo giorno di un certo anno in Aulide, publicada en $1965^{2}$, parece rescatar y recuperar el fuerte sentido político de este personaje y de la obra de los trágicos, añadiéndole, al mismo tiempo, nuevos significados.

Partisano, juez, poeta, dramaturgo, traductor, son solo algunas de la facetas de esta gran figura, que no siempre durante su vida ha sido reconocida y celebrada como hubiera merecido. Quizás también por su excesiva modestia, como destacan estos versos, donde esboza su recorrido como autor dramático.

\author{
Scrissi per il teatro. Che scrivesti? \\ Qualche esempio di umana dignità. \\ i cavalieri senza macchia, Parri e Rosselli, \\ De Bosis, Rosa e i gesti \\ di sfida al male ed al non senso, ai guasti \\ del potere. \\ Tragedie.... \\ Poche schegge \\ forse, di verità. (Faggi 1991: 125)3
}

\footnotetext{
${ }^{1}$ En el reciente libro de Caterina Barone publicado en 2014 y titulado Ifigenia. Variazioni sul mito se analizan las principales relecturas de este mito.

${ }^{2}$ Antes de Un certo giorno di un certo anno in Aulide que se publicó en su versión definitiva en 1965 en Il dramma y se representara en el Teatro Stabile de Catania, Vico Faggi ya había publicado en 1962, en Nuova Corrente, Ifigenia non deve morire que se representó en el Teatro Grande de Brescia.

3 "Escribí por el teatro. Que escribiste?/Algunos ejemplos de humana dignidad/ los caballeros sin mancha,/ Parri y Rosselli, De Bosis, Rosa/ y los gestos de desafío al mal y al no sentido,/ a los fallos del poder./Tragedias.../Pocas astillas/ quizás, de verdad”. Todas las traducciones de las citas desde el italiano al español, son personales.
} 
Roberto Trovato ha observado cómo Faggi se caracteriza constantemente por el deber de actuar y la voluntad de implicarse con su teatro "vuole provocare e sollecitare la soluzione di problema etici e politici. La parola infatti non è mero dialogo ma piuttosto investigazione e scoperta delle ragioni del presente" (Trovato 1991: XIV).

En la misma línea se posiciona Gianni Dagnino que en el no 9 de la Riviera Ligure de 1992 lo describía como un hombre en continua búsqueda de la verdad o de la esencia de la naturaleza humana. Toda su obra se ha puesto como objetivo ofrecer una clave de lectura de la realidad que el autor consideraba el verdadero deber de quien trabajaba en un ámbito cultural: "Compito dell'intellettuale è quello di capire e far capire. L'intellettuale deve essere la coscienza critica di una società, della società cui appartiene"4.

A propósito de Vico Faggi, Ugo Ronfani (1992) ha observado que el objetivo de su dramaturgia siempre ha sido restituir al teatro la antigua función de templo laico, donde resuenan mensajes humanos, civiles y políticos, y la lección de los trágicos griegos y su capacidad de analizar y describir la realidad y los caracteres se advierte a lo largo de toda su obra. Umberto Albini, que ha colaborado en varias traducciones con él, ha subrayado como el teatro de Faggi siempre ha representado "il secondo modo, e non il meno importante, che egli si è scelto per servire la giustizia” (Albini 1976: 71).

En Vico Faggi, como ya en los trágicos griegos, el sacrificio inminente de Ifigenia es el instrumento que permite indagar en las relaciones entre los protagonistas, es una lupa que se focaliza sobre sus ánimos y sus acciones. E1 sacrificio es el punto de partida para una reflexión profunda sobre el poder de la relaciones de fuerza. Como observa Giuseppe Gazzola (1997), en esta obra el autor realiza una denuncia de la política disfrazada de religión y estigmatiza el interés personal que se impone como razón de estado.

El mito sirve a Faggi para interpretar la realidad de su tiempo y también para llenar el vacío y el nihilismo que caracteriza su actualidad, que pero también podrían ser de nuestros días. La tragedia de Faggi, como la tragedia de Eurípides, que el autor bien conoce por su amplia trayectoria también como traductor, se propone insinuar dudas, provocar preguntas en el lector/espectador, que no puede ser simplemente un elemento pasivo ${ }^{5}$. El teatro de Faggi es un teatro de acción que confía en el poder de la palabra para sanar y mejorar el mundo, que quiere tomar posición e intentar encontrar una solución posible.

\footnotetext{
${ }^{4}$ Cita recogida en Trovato, R., "Premessa", in Le armi della ragione. Contributo allo studio dell'opera teatrale di Vico Faggi: 5.

${ }^{5}$ En su introducción al volumen de Vico Faggi, Parola di teatro. Sei commedie, Roberto Trovato subraya que el autor tiene presente para relectura el episodio del primer libro del $D e$ Rerum Natura de Lucrecio pero sin utilizar los mismos tonos patéticos, sino señalando los crímenes cometidos en nombre de los intereses personales.
} 
Vico Faggi construye su obra como un juicio de lo ocurrido en Áulide a través de dos testigos: el testigo en blanco y el testigo en negro. Desde el comienzo de la obra, las palabras de los dos testigos nos ofrecen una interpretación opuesta del mismo acontecimiento. Mientras el testigo en blanco se interroga con espíritu crítico y reflexiona de manera profunda sobre lo que se presenta como verdad absoluta e indudable, el testigo en negro acepta y no discute la ideología dominante.

IL Testimone in Bianco - Mai, occhio umano vide fatto più atroce, orecchio udì parole più terribili.

IL Testimone in Nero - Mai dico mai, occhio umano vide più nobili eventi, mai orecchio ascoltò parole più sublimi.

Il Testimone in Bianco - Mai delitto più vile fu consumato...

IL Testimone in Nero - Mai sacrificio più puro fu celebrato...

Il Testimone in Bianco - Nel nome della civiltà...

Il Testimone in Nero - Della patria...

Il Testimone in Bianco - Della religione

Il Testimone in Nero - Della religione. (Faggi 1992: 5) ${ }^{6}$

Vico Faggi pone en boca de los dos testigos las mismas palabras, pero con significados opuestos, destacando cómo un mismo episodio puede ser interpretado de manera arbitraria, subrayando cómo quien cuenta la historia puede manipularla según sus propios intereses.

El testigo blanco, que sustituye al clásico coro, y al cual el autor confía su palabra, reivindica la utilidad de la historia para no olvidar el pasado, para que todo el mundo sepa lo que no ha podido vivir en primera persona. En las palabras del testigo blanco se puede leer una referencia directa a lo que ha sido la Resistencia Italiana, en la que el partisano Vico Faggi participó y que es un recuerdo todavía reciente, cuando escribe su obra.

La gran actualidad de la Ifigenia de Vico Faggi es que se trata de una historia que no está anclada al mundo griego y a un escenario lejano, y todavía hoy en día, a más de 50 años de su composición, mantiene intacto su espíritu y puede representar una metáfora perfecta de todas las guerras combatidas sin una motivación real e impuestas desde arriba. La obra de Faggi representa una profunda

${ }^{6} \mathrm{El}$ testigo en blanco - Nunca el ojo humano vio un hecho mas atroz, ni se oyeron palabras tan terribles.

El testigo en negro - Nunca digo nunca ojo humano vio eventos tan nobles, nunca se oyeron palabras tan sublimes. El testigo en blanco - Nunca delito más vil fue perpetuado. E1 testigo en negro - Nunca sacrificio más puro fue celebrado. El testigo en blanco - En nombre de la civilización. El testigo en negro - De la civilización. El testigo en blanco - De la patria El testigo en negro - De la patria. El testigo en blanco - De la religión. El testigo en negro - De la religión. 
e intensa reflexión sobre la incoherencia, la absurdidad y la imposibilidad de encontrar justificaciones plausibles?

El adivino Calcante, para poder proseguir con la guerra, apela a razones religiosas y una lucha contra el Oriente que suena muy actual:

Calcante - Dall'oriente ci è giunta una sfida che non possiamo ignorare [...] Là si annidano i barbari. Se non li combattiamo oggi, se non li pieghiamo al più presto, i loro appetiti cresceranno, aumenterà la loro audacia e prepotenza e saranno loro ad attaccarci, nel momento che giudicheranno più propizio [...] Gli dei sono con noi, cin la civiltà contro la barbarie. (Faggi 1992: 8-9) ${ }^{8}$

La paradoja es que la lucha contra la barbarie se construya con un acto bárbaro como cortar la garganta a una joven virgen. En este contexto, y bajo las presiones también de Odiseo, la elección de Agamenón es consecuente y llega muy pronto: declarar lealtad a su patria y sacrificar a su hija. Como advierte el testigo blanco, en realidad, las decisión no ha sido tan simple y así la obra, con una técnica cinematográfica, procede a través de varios cuadros que ilustran otros escenarios posibles, flashback, escenas paralelas.

En el cuadro tercero cada personaje parece tener una propia razón para empezar la guerra: Menelao quiere recuperar a su esposa Elena, pero el testigo blanco desmonta sus razones: "Elena se ne è andata di sua volontà, nessuno l'ha costretta. Suvvia lo sanno tutti" (Faggi 1992: 11)`, el poeta épico sostiene que hay que morir por Elena, porque ella representa el concepto de belleza, la fascinación de la aventura, del escalofrío, pero habla así porque no sabe de verdad qué es la guerra, la ha narrado, pero no la ha probado sobre su piel. El poeta elegiaco, al contrario, considera la guerra un mal, pero un mal necesario, la "extrema ratio" que el hombre necesita para endurecerse y purificarse, y el poeta para poder tener una inspiración para su obra.

${ }^{7}$ Un poema de Wim Wenders, titulado La ragione smarrita y publicado el 28 mayo en el periodico italiano Repubblica, reflexionaba sobre las mismas temáticas a proposito de la guerra del Kosovo:

"Sono tante le cose che non comprendo/ di questa guerra e così poche quelle che afferro./ Una sola mi sembra abbastanza certa:/ ogni guerra è una guerra./ Ogni guerra finisce per mangiarsi le sue ragioni quand' anche/ fossero le migliori. E continuo a pensare/ che combattere il male con altro male non può, alla fine,/ essere un bene".

${ }^{8}$ Calcante - Desde Oriente nos ha llegado un desafío que no podemos ignorar [...] Allí se esconden los barbaros, si no los combatimos hoy, si no los sometemos pronto, sus deseos crecerán, aumentarán su audacia y prepotencia y serán ellos a atacarnos en el momento que consideren mas propicio. [...] Los dioses están con nosotros, con la civilización contra la barbarie.

9 "Elena se ha marchado porque ella ha querido, nadie la había obligado. ¡hombre! todos lo saben". 
Odiseo pasa a describir la muerte de la víctima del sacrificio en un pathos creciente, donde la imagen de la sangre derramada parece excitar cada vez más a Menelao. A tal propósito Nicole Loraux (1985) sostiene que el sacrificio violento de una virgen permitía a los griegos pensar lo impensable y les daba la posibilidad de trasgredir e imaginar la dimensión de lo prohibido, constituido por el asesinado, y contemporáneamente soñar con la sangre de las vírgenes. No es casualidad que la representación trágica del sacrificio recuerde en muchas ocasiones la violencia sexual de un pandilla donde una persona actúa (violando/ matando), mientras los demás compañeros lo incitan y aclaman. Sin embargo, cuando Calcante desvela que la victima tendrá que ser Ifigenia, Agamenón reacciona con violencia y lanza acusaciones a los compañeros y se dice decidido a disolver el ejército.

En el cuadro siguiente se destaca el punto de vista de los soldados, a los cuales el autor otorga la parte tragicómica de la obra. Ellos también son de una cierta manera víctimas del poder y de la política. En el diálogo de los cuatro soldados, se hace hincapié en el hecho de que quien está en primera línea casi siempre combate una batalla que no siente suya y que en muchos casos tiene causas fútiles.

IL PRIMO SOLDATO - Allora è deciso?

Il SECONDO SOLDATO - Cosa?

IL PRIMO SOLDATO - Che dobbiamo farci sbudellare per Elena. (Faggi 1992: 14) ${ }^{10}$

Los soldados siguen dialogando sobre cómo Elena 'ponía los cuernos' a Menelao y cómo Odiseo sostiene que se tratará de una guerra relámpago (también en este caso no nos faltan los ejemplos en la historia reciente, pensamos por ejemplo a la guerra en Iraq anunciada como guerra relámpago que duró nueve años). En realidad, Odiseo hace pura propaganda y su real motivación es escapar de Penélope. El diálogo entre los soldados concluye con una serie de rápidas réplicas, digna del mejor Aristófanes. La conclusión es que una vez más el destino de muchos (los pobres), está en manos de pocos (los ricos) y no hay ninguna posibilidad de salida ${ }^{11}$.

${ }^{10} \mathrm{El}$ primer soldado - Ya está decidido. El segundo soldado - ¿Qué? El primer soldado Que tenemos que hacernos destripar por Elena El segundo soldado - Así dicen.

${ }^{11} \mathrm{El}$ primer soldado - Si tú dices: será una guerra relámpago, Odiseo te contesta: es por eso que la ganaremos. Si tu dices que será una guerra larga, Odiseo te contesta: es justo por eso que la ganaremos. ¿Qué significa? El segundo soldado - No sé...que la ganaremos en cualquier caso. El primer soldado - No, que se cree que somos tontos! El tercer soldado - Menelao hace la guerra porque su mujer es guapa. Odiseo hace la guerra porque su mujer es fea. ¿Y tú que eres soltero porque la haces? El cuarto soldado - Porque la haces tú. El tercer soldado - Pero yo no la hago porque tú la haces. El cuarto soldado - Entonces es fácil, no la hago más. El tercer soldado - Bien me has convencido. Ahora solo queda convencer Odiseo. El cuarto 
En el cuadro siguiente se representa el encuentro entre Agamenón e Ifigenia, que recalca bastante fielmente el de la tragedia de Eurípides y está construido sobre el equivoco boda/sacrificio a través de una eficaz ironía trágica. Respecto al precedente de Eurípides, Faggi va más allá y crea un contraste entre las palabras patria y madre, poniendo en evidencia cómo la sociedad patriarcal intenta apoderarse también del concepto de maternidad.

Ifigenia - Ma tu sei mio padre! Non puoi abbandonarmi. Che c'entro io con la salvezza della patria...

Agamennone - [...] Se non ti sacrifico, dovrò sacrificare la patria. Tu sei mia figlia, la prediletta, ma la patria è madre di noi tutti.

IFIGENIA - La vita è mia! L'Ellade no è che una parola.

Agamennone - L'Ellade non è un nome soltanto, tu lo sai, è il sangue che scorre nelle nostre vene, la lingua che parliamo, la nostra civiltà, il nostro modo di vivere. Solo il pensiero della patria ha potuto vincere il mio cuore di padre. (Faggi 1992: 19)12

Llegados a este momento, como ya en Eurípides, Ifigenia cambia de repente opinión y se dice dispuesta a morir y parece mostrar su faceta patriótica y guerrillera, que insiste nuevamente en el conflicto Occidente/Oriente:

Ifigenia - Che conta la mia vita? La vita di una donna? Penso al tuo strazio, padre mio, ma tu non mi hai generata solo per te, ma per tutta la Grecia? [...] Immolatemi, ma distruggete Troia! Le sue rovine saranno il monumento eretto alla mia memoria, assai più glorioso che illustre nozzi e numerosi figli. (Faggi 1992: 20) ${ }^{13}$

En Eurípides el cambio de Ifigenia ante el sacrificio condicionaba también su manera de expresarse y relacionarse con los demás personajes. Si en la primera parte del diálogo con el padre actuaba en un ámbito emocional, en esta segunda fase su actitud resulta extremadamente racional. No habla como una virgen

soldado - Imposible. Tiene una mujer fea. El tercer soldado - Inténtalo con Menelao. E1 cuarto soldado - Imposible, tiene una mujer guapa. El tercer soldado - Maldición! La guerra no se puede propio evitar.

12 Ifigenia - Tú eres mi padre. No puedes abandonarme. ¿Qué tengo que ver yo con la salvación de la patria? Agamenón - [...] Si no te sacrifico tendré que sacrificar la patria. Tú eres mi hija, la mas querida, pero la patria es la madre de todos nosotros. Ifigenia - La vida es mía! Grecia solo es una palabra. Agamenón-Grecia no es solo un nombre. Tú lo sabes, es la sangre que corre por las venas, el idioma que hablamos, nuestra civilización, nuestro modo de vivir. Solo la idea de la patria ha podido vencer mi corazón de padre.

${ }^{13}$ Ifigenia - ¿Qué cuenta mi vida? ¿La vida de una mujer? Pienso en tu tormento padre, pero tú no me has generado solo para ti, sino para toda Grecia. [...] Inmoladme pero destruís Troya! Sus ruinas serán el monumento erigido a mi memoria, mas glorioso que nobles bodas y numerosos hijos. 
sino como un guerrero, y reivindica el bien de Grecia, la gloria, subrayando la necesidad de vengar la ofensa que su pueblo ha recibido. Andò (2008) observa que la elección de Ifigenia de lo simbólico patriarcal se manifiesta, también, en la decisión de interrumpir su relación con la madre, Clitemnestra, como si temiese contaminar su nueva dimensión viril.

En cambio, Vico Faggi puntualiza, a través de las palabras del testigo en blanco, que el encuentro entre Ifigenia y Agamenón fue bastante diferente ${ }^{14}$. E1 cuadro sexto muestra como Ifigenia insultó varias veces a su padre, que se vio obligado a utilizar la violencia para reducirla.

Agamennone - (torcendole il braccio e facendola cadere in ginoccbio) Devi morire, è già deciso. Non puoi farti illusioni. [...] Dovessi frustarti a sangue, farò che ti comporti come il tuo rango impone. (Faggi 1992: 21-22) ${ }^{15}$

Vico Faggi en su obra contrasta en varias ocasiones el principio maquiavélico de que "el fin justifica los medios" y reafirma que es necesario resistir, luchar hasta el último respiro, como en el diálogo entre Ifigenia y Aquiles en el segundo acto, único rayo de esperanza dentro del escenario turbio de toda la obra. Aquí Aquiles es diferente a la imagen del héroe invencible y despiadado de la Ilíada, y se muestra como un personaje sensible, pronunciando frases que evocan respeto por lo que no se conoce, del otro, de lo que es diferente:

Achille - È facile condannare una persona che non abbiamo mai visto, di cui non sappiamo nulla. Basta qualche argomento per convincerci, che so, la ragion di Stato, l'interesse della patria...Ma quando una persona la conosci, l'hai guardata negli occhi, sai quello che pensa, allora le ragioni non contano più. Espedienti, menzogne...Resta soltanto il delitto. (Faggi 1992: 28) ${ }^{16}$

Se puede leer en las palabras de Aquiles una referencia al drama de la Resistencia y de los partisanos que se ven obligados a matar para poder sobrevir. Se trata de un tema y de una realidad que Faggi ha conocido de cerca durante los años de la Segunda Guerra Mundial y ha tratado también en algunos de sus

${ }^{14}$ Sigue también la representación de otro posible escenario donde Ifigenia confiesa al padre haber soñado con un adulterio y ahora quiere morir por la vergüenza.

${ }_{15}$ Agamenón - (torciéndole el brazo y haciéndola caer de rodillas) Tienes que morir ya está decidido. No te hagas ilusiones [...] Si fuera necesario te golpearé con el látigo para que mantengas un comportamiento como lo exige tu rango.

${ }^{16}$ Aquiles - Es fácil condenar una persona que no hemos visto nunca, de la que no sabemos nada! Es suficiente algunos argumentos para convencernos, como la razón de estado, el interés de la patria...pero cuando conoces a esa persona, la has mirado en los ojos, sabes lo que piensa, entonces las razones ya no cuentan. Triquiñuelas, mentiras... solo queda el delito. 
poemas dedicados a la Resistencia ${ }^{17}$.

Aquiles representa, junto con el testigo blanco e Ifigenia, la ética que resiste y no se rinde al estado y a los poderes fuertes. Su personaje, después del encuentro con Ifigenia y su cruce de miradas, cambia radicalmente y adquiere una mayor conciencia de sí mismo y de la realidad que tiene a su alrededor.

É vero, una volta non ero che una parte di Patroclo, la sua ombra. Per la prima volta, ora, mi sento me stesso. Sono Achille e basta. Ho raggiunto d'un tratto ciò che da anni, inconsapevole, cercavo. Ed è stato semplice: bisognava soltanto guardare Ifigenia. Questo non l'avevo mai posseduto e ora non lo lascerò. Il senso di essere io, separato dagli altri e tuttavia capace di capirli. Un essere umano. Gettato qui, ma libero di scegliere. (Faggi 1992: 32) ${ }^{18}$

En un cuadro sucesivo se muestra también el encuentro entre Agamenón y Clitemnestra, donde el padre de Ifigenia sostiene una vez más que sus motivos son los de la razón y no los del corazón que mueven a su mujer. Se trata de una razón patriarcal, que puede mas que el vínculo matrilineal, que el sacrifico está a punto de interrumpir: "Io sono un uomo di Stato, capo di una città e di una dinastia [...] un uomo chiamato al comando, gli piaccia o no, deve seguire la sua strada" (Faggi 1992: 40) ${ }^{19}$.

En el cuadro decimotercero los soldados reflexionan nuevamente sobre el sentido y las motivaciones de la guerra. Pero a pesar de estar todos de acuerdo sobre la inutilidad e insensatez, prevalece el miedo a rebelarse:

IL TERzo SOLDATO - È vero, la guerra è una pazzia, questa più di tutte. Dovremmo ribellarci, tornare tutti a casa.

Il PRIMO SOlDATO - Perché non cominci tu?

Altri - (in coro) Anch'io. Anch'io.

IL QUARTO SOLDATO - Io ho moglie e quattro figli. Anche la suocera a mio carico. IL PRIMO SOLDATO - Tutti hanno famiglia. Forse è per questo che scoppiano le guerre. (Faggi 1992: 46) ${ }^{20}$

${ }^{17}$ También la escritora Elena Bono que transcurrió en Liguria los años de la Resistencia, llevando recados en las montañas de Calvari, en su cancionero sobre la Resistencia en más de una ocasión se enfrenta con esta temática, como por ejemplo en el poema Lamento di David sul gigante ucciso.

${ }_{18}$ Aquiles - Es verdad una vez no era más que una parte de Patroclo, su sombra. Por primera vez ahora me siento yo mismo. Soy Aquiles y nada mas. He conseguido de repente lo que estaba buscando desde hacía años. Y ha sido simple, solo tenía que mirar a Ifigenia. Esto no lo había tenido nunca y ahora no lo dejaré. El sentido de ser yo, separado de los demás pero aún así capaz de entenderlos. Un ser humano. Tirado aquí pero libre de elegir.

${ }^{19}$ Agamenón - Yo soy un hombre de estado, jefe de una ciudad y de una dinastía. [...] un hombre llamado al comando, le guste o no, tiene que seguir su camino.

${ }^{20}$ Tercer soldado - Es verdad, la guerra es una locura, esta más que ninguna. Debiéramos rebelarnos, volver todos a casa. 
Después Aquiles encuentra por la última vez Ifigenia, le promete su apoyo y le confirma que no la dejará sola:

ACHIlle - Il mio dovere è resistere, lottare sino all'ultimo respiro. Non bisogna cedere al male. I carnefici vogliono il consenso della vittima, la sua comprensione, la sua complicità. Vogliono che il delitto si mascheri da sacrificio. (Faggi 1992: 49) ${ }^{21}$

Ahora Ifigenia sabe que su destino es la muerte, pero a diferencia de la Ifigenia de Eurípides elige de verdad cómo morir y cómo sobrevivir en el recuerdo de los demás:

Ifigenia - La verità è che la morte mi attende. Non mi resta che scegliere la morte più bella. [...] Li guarderò negli occhi con disprezzo. Tu resterai a ricordarmi. [...] Solo tu hai conosciuto Ifigenia. Io vivrò in te, se tu vivrai [...] Salvati, ricordami. (Faggi 1992: 50)22

Una vez que Calcante ha cumplido el sacrificio, los dos testigos aparecen en la escena por última vez, para contar la propia verdad. El testigo en negro cuenta la versión del mito que ya se conoce desde Eurípides, con la sustitución de Ifigenia con una cierva, en cambio el Testigo en blanco, mientras tiene en los brazos el cuerpo sangrante de Ifigenia, invita al público a actuar con determinación sin llorar ni tener piedad. Una advertencia que mantiene intacta su fuerza y sigue siendo una lección necesaria para las futuras generaciones.

Il testimone in bianco - Giudicate, uomini. Voi dovete giudicare. Ifigenia è morta, la sua giovinezza se ne è andata col sangue che colava dalle ferite. Non credete ai poeti che mentono, sputate sui falsi testimoni. Ifigenia non vivrà, nessuna dea l'ha salvata. Eccola è morta. Non lasciate che le belle parole vi ingannino. L'hanno uccisa ed è stato un delitto che ne prepara uno più grande, la guerra, che genererà nuovi delitti. Ifigenia, non si è offerta al sacrificio, l'hanno trascinata, ed ella urlava, si dibatteva, li ingiuriava. L'hanno sgozzata come una bestia mentre Achille veniva sopraffatto. Giudicate, uomini. Il

Primer soldado - ¿Porque no empiezas tú? Tercer soldado - No querrás que me haga notar, tengo familia. Otros - (en coro) Yo también. Yo también. Cuarto soldado - Yo estoy casado y tengo cuatro hijos. También mi suegra está a cargo mío. Primer soldado - Todos tienen familia. Quizás es por eso que empiezan las guerras.

${ }^{21}$ Aquiles - Yo me quedaré contigo. [...] Mi deber es resistir, luchar hasta al último respiro. No debemos ceder al mal. Los verdugos quieren el consenso de la víctima, su comprensión, su complicidad. Quieren que el delito sea enmascarado como sacrificio.

${ }^{22}$ Ifigenia - La verdad es que la muerte me espera. Solo me queda elegir la muerte mas bella. [...] Los miraré en los ojos con desprecio. Quedarás tú para recordarme. [...] Solo tú has conocido Ifigenia. Yo viviré si tu vivirás. [...] Sálvate, recuérdame. 
delitto è stato consumato, nessuno ha saputo impedirlo. Achille ha cercato ma era solo. Ditelo voi: l'uomo che si oppone al male dovrà sempre essere solo? Uomini, svegliatevi. Non serve chiudere le porte e le finestre. Le pietà e le lacrime non servono. Quando è tempo di agire, chi sa offrir soltanto lacrime è un nemico. (Faggi 1992: 53) ${ }^{23}$

A siglos de distancias, Vico Faggi consigue releer la historia de Ifigenia y enfrentarse con temas que nunca envejecen, como la responsabilidad civil, la representación del concepto de patria, la religión, la influencia de lo político en la sociedad. También nos recuerda la importancia de conservar la memoria histórica, único antídoto para resistir ante el olvido, y la necesidad de defender la verdad ante cualquier manipulación o violencia.

${ }^{23}$ Testigo en blanco - Juzgad hombres. Tenéis que juzgar. Ifigenia ha muerto, su juventud se ha ido con la sangre que goteaba desde sus heridas. No creáis a los poetas que mienten, escupid sobre los falsos testigos. Ifigenia no vivirá , ninguna diosa la ha salvado. Aquí está, muerta. No dejéis que las palabras hermosas os engañen. La han matado y ha sido un delito que prepara uno mas grande, la guerra, que generará nuevos delitos. Ifigenia no se ha ofrecido al sacrificio, la han arrastrado y ella gritaba, se debatía, los injuriaba. Le han cortado la garganta como a un animal mientras Aquiles era derrotado. Juzgad hombres. El delito se ha cumplido, nadie ha sabido impedirlo. Aquiles lo ha intentado pero estaba solo. Decirlo vosotros: el hombre que se opone al mal siempre ¿tendrá que quedarse solo? Hombres despertad. No sirve cerrar las puertas y las ventanas. La piedad y las lágrimas no sirven. Cuando es tiempo de actuar, quien sabe ofrecer solo lágrimas es un enemigo. 


\section{Obras citadas}

Albini, U. (1976), "Il teatro di Faggi è scomodo", prefazione a Giochi di fine d'anno, Sipario, dicembre, no 367.

Andò, V. (2008), "Un corpo di donna per fare la guerra. Lettura della Ifgenia in Aulide di Euripide", in Storia delle donne. Firenze, University Press: 71-82.

Barone, C. (2014), Ifigenia. Variazioni sul mito. Venezia: Marsilio.

Beltrametti, A. (2008), "Ifigenia e le altre. Archetipi greci del sacrificio, oblazione eroica e crimine politico nella cultura ateniese del V secolo", in Storia delle donne. Firenze, University Press, IV: 47-69.

Cavarero, A. (2009), Horrorismo. Nombrando la violencia contemporánea. Barcelona: Anthropos.

Cerrato, D. (2010), "Il sacrificio femminile come forma di violenza nella tragedia greca”, in Gonzalez De Sande, M., La imagen de la mujer y su proyección en la literatura, la sociedad y la historia. Sevilla, Arcibel editores: 79-89.

Cerrato, D. (2011), "Cuerpos vulnerados. La violencia contra las mujeres a través del mito", in Ramírez Almazán, D., In Corpore Domina. Sevilla, Arcibel: 69-92.

Dagnino, G. (1992-1993), "Un pensiero su Vico Faggi”, La Riviera Ligure 3. 9: 4-6.

Diano, C. (1970), Il teatro greco: tutte le tragedie. Firenze: Sansoni.

Euripide (1992), Ifgenia in Aulide, Ifgenia in Tauride. A cura di Vico Faggi. Torino: Einaudi.

Faggi V., Orengo A., (1991), Il giudice e il poeta. Genova: Marietti.

Faggi, V. (1992), Parola di teatro. Sei commedie. A cura di R. Trovato. Genova: Marietti.

Faggi, V. (1998), Vero e verisimile: commedie. A cura e con prefazione di R. Trovato. Alessandria: Edizioni dell'Orso.

Faggi, V. (2007), Scrivere teatro. Recco (Genova): Le Mani.

Gazzola, G. (1997), Le armi della ragione. Contributo allo studio dell'opera teatrale di Vico Faggi. Recco (Genova): Microart's.

Loraux, N. (1985), Façons tragiques de tuer une femme. Textes du XX Siècle. Paris: Hachette.

Puccini, D. (1992-93), "Vico Faggi poeta”, La Riviera Ligure 3. 9: 7-12.

Reverdito G. (1992-93), "Vico Faggi traduttore”, La Riviera Ligure 3. 9: 19-22.

Ronfani, U. (1992-93), "Il Teatro del Giudice”, La Riviera Ligure, 3. 9: 13-18.

Trovato, R. (1989), Il teatro di Vico Faggi. Forlí: Forum/Quinta generazione. 
Trovato, R. (1989), "Vico Faggi, un drammaturgo che interroga la storia", Hystrio 4: 57-60.

Trovato, R. (1992), "Introduzione", in Faggi, V., Parola di teatro. Sei commedie. A cura di R. Trovato. Genova, Marietti: VII-XXVIII. 